\title{
Cyclin B1 Protein Expression in Oral Dysplasia and in Oral Squamous Cell Carcinoma - "Animmunohistochemicalstudy".
}

\author{
Dr. Santosh kumar Kotnoor MDS ${ }^{1,}$ Dr. Bhalkeshwar ${ }^{2}$ \\ Dr. Rohini V Junjunappanavur MDS ${ }^{3,}$ Dr. Gurucharan Donekal ${ }^{4}$, \\ Dr. Pavankhichade ${ }^{5}$, Dr. Shivraj S Patil ${ }^{6}$, Dr. Abhishek Bansal MDS ${ }^{7}$ \\ ${ }^{1}$ Senior Lecturer, Dept Of Oral Pathology, Hyderabad Karnataka education Trust Dental College, \\ Humnabad. Karnataka. \\ ${ }^{2}$ Senior Lecturer, Dept of Conservative and Endodontics, HKDET's Dental College, \\ Hospital and Research Institute, Humnabad.Karnataka. ${ }^{3}$ Private Practitioner \\ ${ }^{4}$ PG Student, Dept. Of Oral Surgery, Al-Badar Dental College and Hospital, Gulbarga. \\ ${ }^{5} P G$ Student, Dept. Of Oral Surgery, Al-Badar Dental College and Hospital, Gulbarga. \\ ${ }^{6}$ PG Student, Dept. Of Oral Surgery, Al-Badar Dental College and Hospital, Gulbarga. \\ ${ }^{7}$ Senior Lecturer, Dept of Orthodontics and Dentofacial Orthopedics, \\ Vaidik Dental College And Research Center, Nani Daman. U.T.
}

\begin{abstract}
Cyclin B1 is a member of the cyclin family of protein whose level vary during the cell cycle in order to activate specific cyclin-dependent kinases (CDKs) required for the proper progression through the cell cycle . the present study is to compare the expression of cyclin BI in normal, dysplastic and squamous cell carcinomas.

Experimental design: To determine the role of cyclin B1 in normal, dysplastic and squamous cell carcinomas, we analysed 60 patients with normal, dysplastic and squamous cell carcinomas.

Results: In control patients that is of twenty patients, six were negative for cyclin B1 expression in basal and parabasal layers and 14 were positive for cyclin B1 expression in basal and parabasal layers.In other group(dysplastic) of twenty patients 3 were negative and 17 were positive for cyclin B1 expression. In other group with squamous cell carcinomas 7 were negative and 13 were positive for cyclin B1 expression.

Conclusion: Our study concludes that although the expression of cyclin BI in dysplastic epithelium is below the cut of point (15\%) but the expression was conisiderly high and this indicates that the patients with dysplastic are more susceptible for further changes, including progression and development of carcinomas.
\end{abstract}

\section{Introduction}

Carcinogenesis is literally the origination of cancer. It is a process by which normal cells are transformed into malignant cells, characterized by a progression of changes at the cellular, genetic and epigenetic level that ultimately reprogram a cell to undergo uncontrolled division, thus leading to formation of a malignant mass. ${ }^{2}$ Recent insights in the field of cell cycle regulation and cancer have provided prime examples of research at the "frontiers of science". 3

The eukaryotic cell cycle is divided into four stages; G1, S, G2, and M. G1 is a gap phase during which cells prepare for the process of DNA replication. It is during the G1 phase that the cell integrates mitogenic and growth inhibitory signals and makes the decision to proceed, pause, or exit the cell cycle. S phase is defined as the stage in which DNA synthesis occurs. G2 is the second gap phase during which the cell prepares for the process of division. $\mathrm{M}$ stands for mitosis, the phase in which the replicated chromosomes are regulated into separate nuclei andcytokinesis occurs to form two daughter cells. G0 term is used to describe cells that have excited the cell cycle and become quiescent. ${ }^{4}$

Cyclins A, D and E regulates the passage from G1 phase to S phase, where ascyclins A and B direct the transition from $\mathrm{G} 2$ phase to $\mathrm{M}$ phase. Specifically, cylinB1 and cdc2 are the components of the maturation/mitosis-promoting factor, which plays an important role from G2 - M phase transition. Cyclin B1binds to cyclin-dependent kinase2, which then becomes dephosporylated and relocated to the nucleus. Expression of cyclin B1 is cyclic with a minimal expression in G1 phase, an increased level in S phase, and peak at the G2-M transition. However, activecyclin B1/Cyclin-dependent kinase2 complex has been detected in the cytoplasm and is implicated in the formation of mitotic spindle. ThusCyclin B1 through its trafficking between the cytoplasm and the nucleus, seems to play a role in coordinating the mitotic process in both components. ${ }^{4}$ 
Cyclin B1 isoverexpressedin a variety of cancers compared to normal cells and tissues. In normal tissues, low levels ofcyclin B1 is detected in testis, thymus, bone marrow, and smooth muscle (CCNB1 expression).

Overexpression of cyclin B1 has been reported in lung, breast, colon, prostate, and head and neck cancers. ${ }^{5}$ Oral habits such as alcohol consumption and tobacco chewing are considered to be initiators of dysplastic changes in the oral mucosa. ${ }^{6}$ The expression ofcyclin B1 in clinically normal oral mucosa, and in dysplastic changes has not been studied. The present study is to compare the expression of cyclin B1 in normal, dysplastic, and squamous cell carcinomas,so to fill the void in this important field.

Study population.

\section{Materials And Methods}

The patients for the present study are drawn from the outpatient department of S.Nijalingappa institute of Dental Sciences and Research and Basaweshwar Teaching and General Hospital, Gulbarga.

\section{Patient Selection}

The patients selected for the present study were with the following parameters.

Group I: Twenty patients without tobacco chewing or smoking habits and with clinically normal oral mucosa, served as a control group.

Group II: Twenty patients with tobacco chewing or smoking habits. Oral biopsy was done and stained with $\mathrm{H}$ and $\mathrm{E}$ staining to ascertain, the status of epithelial cells.

Group III: Twenty patients with the habit of tobacco chewing with clinical and histopathologically confirmed cases of oral squamous cell carcinoma.

The tissue biopsies of all three groups of the patients were stained with haematoxylin and eosin and subsequently subjected to immunohistochemical staining.Paraffin embedded, $3 \mu \mathrm{m}$ thick tissue section from all 60 patients were stained for cyclin B 1 using primary mouse munocloud antibody (CGNSI) (Santa Cruse United Kingdom). The samples were rehydrated in graded alcohols. To retrieve the antigenicity, the tissue section were treated with pressure cooker using EDTA atpH 8. The pressure cooker was allowed to reach to full pressure (15 psi) and then incubated for 2 minutes. To block Endogenous peroxidase the tissue were covered with peroxide block reagent according to tissue size. Then it is incubated for 10miniutes at room temperature in humid chamber. Section was incubated overnight at $4^{\circ} \mathrm{c}$ with primary anticyclin B 1 at a 1:15 dilution. The sections were processed using standard avidinbiotin immunohistochemistry according to the manufacturers recommendation. DAB - 3, 3 - diaminobenzidinechromozen (HK124 - 5k) was used as a chromo Zen\& commercial hematoxylin was used for counter staining. The recommended positive control tissue for this antibody was thyroid carcinoma tissue.

The cyclin B 1 labeling index was defined as the percentage of tumor cells displaying cytoplasmic or nuclear immune-reactivity and was calculated by counting the number of cyclin B 1 stained tumor cells $\geq 1000$ cells from representative areas of each tissue section we used 15\% labeling index as a cutoff point. Cells were counted in $\geq 4$ fields (at $\times 100)$ in these areas. All slides were scored concomitantly by two investigators.

\section{Results and Observations}

The expression of cyclin B1 in oral mucosal biopsies of different category of patients was assessed by immunohistochemical method by using mouse monoclonal antibody to cyclin B1 protein .The different groups of patients include Group(I) patients with clinically normal mucosa,without the habit of either tobacco chewing or smoking.

Group (II) patients were tobacco chewers and /or smokers

Group(III) patients included were histopathologically confirmed oral sqaumous cell carcinoma cases with habit of tobacco chewing and smoking.

Cyclin B1 expression in various groups of patients(Among 1000 cell counted more than four fields) in \%.

In group I, (control) patients, that is of twenty patients,six were negative for cyclin B1 expression in the basal and parabasal layers. B1 expression.

In group II,three patients were negative for cyclin B1 and seventeen patients were positive for cyclin

In group III,seven patients were negative for cyclin B1 expression and thirteen were positive for cyclin B1 expression. Comparison of cyclin B1expression in different category of patients(Table II,III,IV,IX) Comparison between group I and group II(Table 3) using student T test, T value was $6.90(>1.96$ for $\mathrm{p}=0.05$ ). Comparison between group I and group III (Table 3 ) using student $\mathrm{T}$ test, $\mathrm{T}$ value was $5.13(>1.96$ for $\mathrm{p}=0.05$ ). 
Comparison between group II and group III(Table 3) using student T test, T value was 2.61( $>\mathrm{i} .96$ for $\mathrm{p}=0.05$ ).
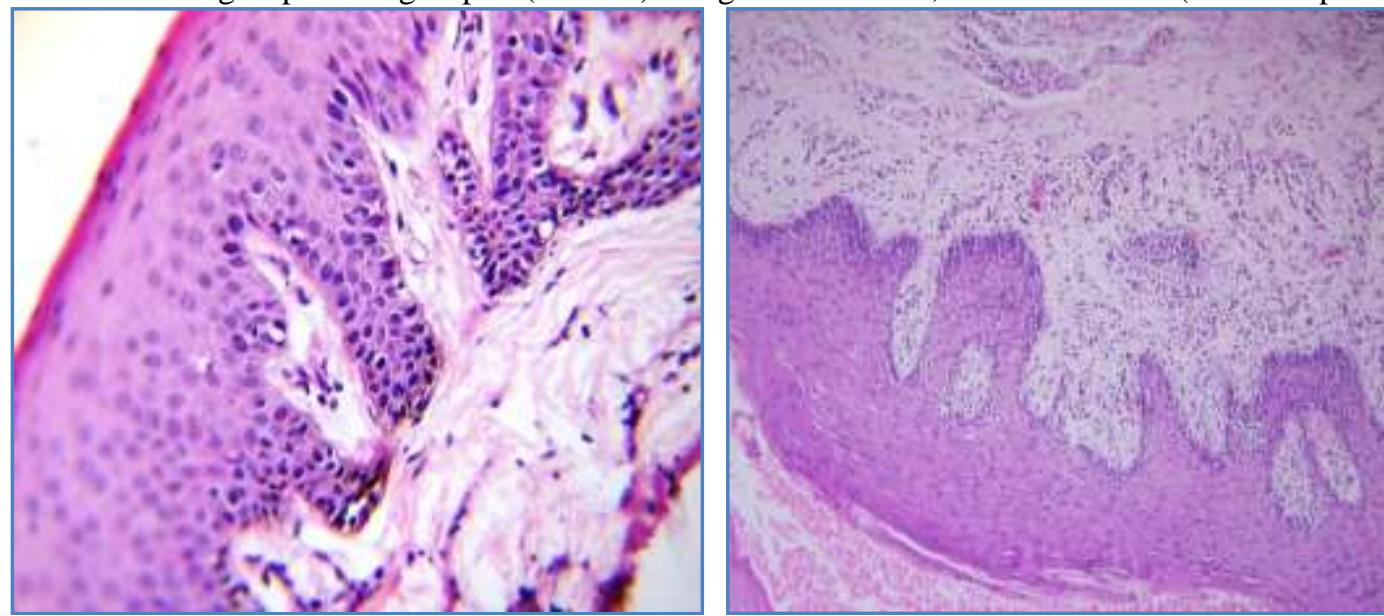

Normal Epithelium (H \& E X 40)Moderate Epithelial Dysplasia (H \& E stain X40)
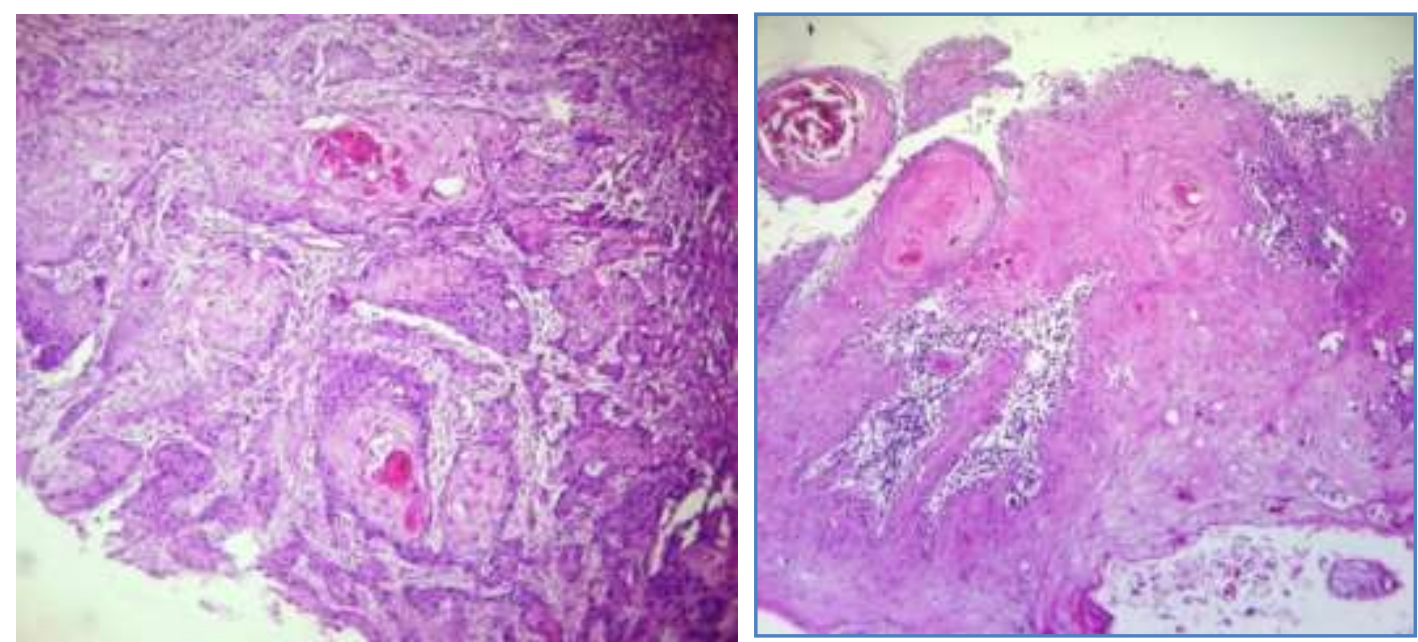

Moderately Differentiated oral SquamousWell Differentiated oral Squamous cell Carcinoma cell(H \& E stain X40) Carcinoma (H \& E stain X40)
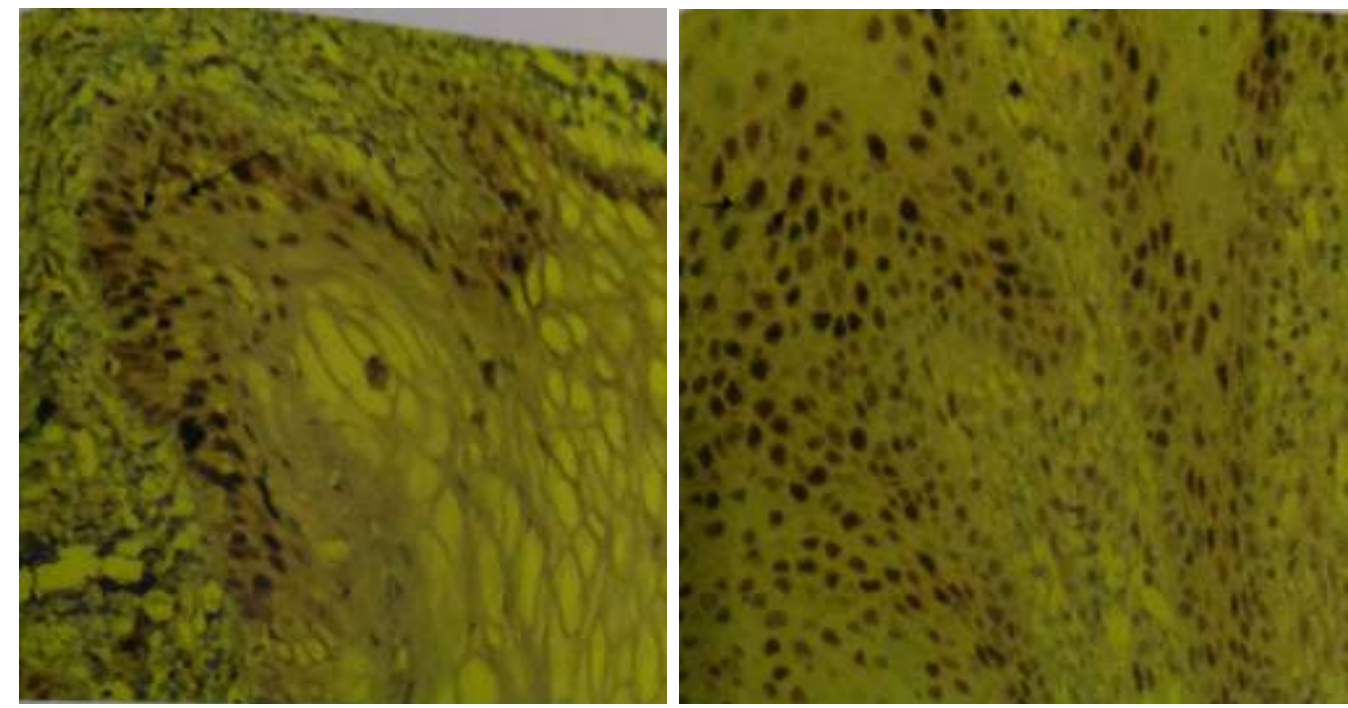

Figure-12: Immuno expressian of çclin B1 ia surmal epitheliua X $20^{\circ}$ $(-)$ Nodear immuno reactivity for çciin BI within the baul layen

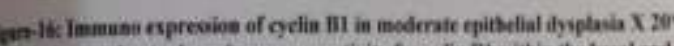

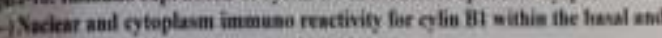
parabasal layer 

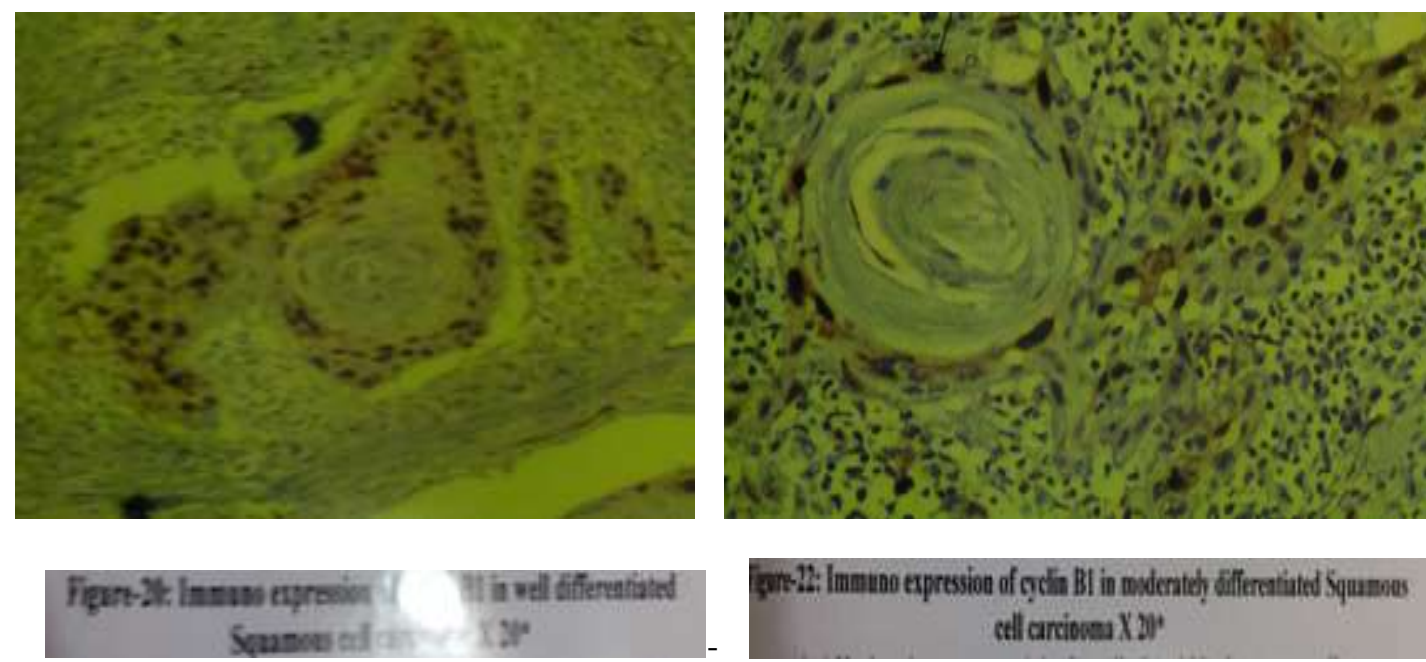

\section{Discussion}

A group of biologically similar cancers that start in the lips,mouth(oral cavity), nose(Nasal cavity ),Para nasal sinuses, pharynx , and larynx are referred to as head and neck cancer. In head and neck region squamous cell carcinoma is the most frequent malignant tumor and account for $90 \%$ of all malignancies. The role of exogenous agents in the etiology of head and neck cancers are tobacco smoking,alcohol intake,oral snuff, dietary factors, occupational exposures, and oral hygiene.

Cigarette smoke contains at least 3500 unidentified chemical constituents, of which nearly $40 \%$ being carcinogenic like polycyclic aromatic hydrocarbons (PAH), such as benzo(a) pyrene(Bap), and 4(n-methyl nitrosamine)-(3-pyridil)-1-butanone (NNK). Relatively fewer carcinogens are present in smokeless tobacco. About 30 carcinogens have been identified, the major contributor being nicotine derived nitrosamines (TSNA). Smokeless tobacco is often combined with other reagents including betel leaf, sliced areca nut and powdered slake lime. These additives used not only enhance the psychotropic effects of nicotine but also make the combination more genotoxic than the tobacco alone. The accompanying use of tobacco and alcohol contributes to increased incidence of head and neck cancers. ${ }^{41}$

The process by which normal cells are transformed into cancer cell is known as carcinogenesis or oncogenesis or tumerigenesis. It is characterized by a progression of changes at the cellular, genetic and epigenetic level that ultimately reprogram a cell to undergo uncontrolled cell division, thus forming a malignant mass. ${ }^{2}$ Eukaryotic cell cycle is divided into four stages, G1, S, G2 and M.G1- the cell prepare for the process of division.S- DNA synthesis occurs.G2- the cell prepares for the process of division.

M (mitosis) - the replicated chromosome are segregated into two separate nuclei to form two daughter cells. ${ }^{4}$ Cyclins were first identified in marine invertebrates as proteins whose accumulation and degradation oscillated during the cell cycle.16 mammalian cyclins have been identified A, B1, B2, C, D1, D2, D3, E, F, G1, $\mathrm{G} 2, \mathrm{H}, \mathrm{I}, \mathrm{K}, \mathrm{T} 1$ and T2. ${ }^{4}$

Of these cyclin B1/cdc2 plays an important role in G2-M transition. The cellular proliferation occurs due to deregulation of this complex and results in uncontrolled cell growth.Cyclin B1 (48.337K Da) is a member of the cyclin family of proteins. Theirlevel varyduring the cell cycle, which is to activate specific cyclin dependent kinases (CDKs), which is essential for the proper progression through the cell cycle. In G2 phase cyclin B1 proteins begins to increase, becomes peak in mitosis, and is rapidly degraded before the cell cycle is completed.Cyclin B1 interacts with CDK1 to form a complex known as the maturation promoting factor (MPK), which is essential for cell cycle progression through mitosis. ${ }^{5}$

After proper alignment of chromosome during the anaphase, the degradation of cyclin B1 occurs by anaphase promoting complex/cyclosome $(\mathrm{APC} / \mathrm{C})$ to exit mitosis, and thus cell cycle is completed. ${ }^{5}$ The overexpression of cyclin B1 may be due to improper degradation or may be due to increased synthesis, localization because of failure of nuclear/cytoplasm homeostasis. ${ }^{36}$ Over expression of cyclin B1 was seen to be positively correlating with other proliferation markers such as cyclin A, ki-67 in oral carcinomas. ${ }^{31}$ Over expression of cyclin B1 was noticed in squamous cell carcinomas of the tongue, cervical lymph nodes. ${ }^{36}$

In this present study cyclin B1 expression was studied by immunohistochemical method using santa cruse mouse monoclonal antibody in dysplastic epithelium (tobacco and smokers) and oral cancer. The results were compared with immunohistochemically stained sections of twenty control subjects. Cyclin B1 expression was not observed in eight of the control cases. This is consistent with previous studies of absence of cyclin B1 expression in normal mucosal biopsies. ${ }^{36,40}$ 
Twelve cases of control group showed cyclin B1 expression in nuclei of the cellsin basal and parabasal epithelial layers consistent with the proliferative compartment of stratified squamous epithelium. This is consistent with previous study of cyclin B1 expression in basal and parabasal layers of normal mucosa. ${ }^{36.40}$

In the present study cyclin B1 expression was found in 17 (85\%) of the twenty cases of tobacco users. Among six mild dysplasia cases four cases expressed for cyclin B1 accounting for $66.67 \%$.Among the six moderate dysplasia cases, five expressed for cyclin B1 accounting for 83.33\%.Among eight cases of severe dysplasia, seven expressed for cyclin B1 accounting for $87.5 \%$. Khaled.A.et.al conducted a study on ten cases of dysplastic epithelium and observed the expression for cyclin B1 in only three cases, that is $30 \%$. In our study we found that there is step wise increase in the expression of cyclin B1 from mild to severe, although they are below cutoff point that is $15 \%$ to be considered as tumor(1000 cells counted in more than four fields).

Expression of cyclin B1 in oral squamous cell carcinoma patients habituated to tobacco in our study was observed in 13 of the 20 cases of histopathologically confirmed cases(65\%). And for tumor cells the cutoff point we included was 15\%(1000 tumor cells in more than four fields, and remaining were taken as negative).

In our studies the expression of cyclin B1 was observed in both nucleus and cytoplasm. Studies done by khaled .A.etal, the cyclin B1 expression was observed in the cytoplasm. The nuclear expression of cyclin B1 may be due to cyclin B1 tends to move from cytoplasm to nucleus with grades of conventional oral squamous cell carcinomas thus increasing the mitotic index in higher grades.Gururaj.B.Patil et.al.

The phenomenon for the expression of cyclin B1 in the cytoplasm is unclear,but one explanation could be that nuclearlocalization could be transient, where as cytoplasmic accumulation is continuous throughout the cell cycle in premalignant and malignant lesions.Khaled.A.et.al. ${ }^{36}$

Another explanation may be that anticyclin B1 antibody has a higher affinity to cytoplasmic cyclin B1 because of epitopicmodifications. ${ }^{36}$ Most of the well differentiated oral squamous cell carcinomas, the cyclin B1 expression was detected in six cases with percentage being $75 \%$.Among seven moderately differentiated oral squamous cellcarcinomas, three cases were detected as cyclin B1 positive with the percentage being $42.85 \%$.Among five cases of poorly differentiated carcinomas, the cyclin B1 expression was detected in four cases with the percentage being $80 \%$.But when we compared statistically by student $\mathrm{T}$ test between moderately differentiatedand poorly differentiated oral squamous cell carcinomas it showed no significance.

The percentage of cyclin B1 expression in OSCC was (65\%) compared with the percentage of dysplastic lesions (85\%), and we also found a large percentage of cyclin B1 expression in high dysplasias (87\%)which may be indicative of increased traverse through the cell cycle,occurring early in tumor progression. ${ }^{36}$

With regards to cyclin B1 expression and grading in oral squamous cell carcinomas,cyclin B1 expression was increased with decrease in differentiation except in moderately differentiated oral squamous cell carcinomas. We observed a predominant cyclin B1 expression in the cytoplasm as well as in the nucleus of the tumor cells.This is incontrast to the study done by Khaled et.al where predominant expression was in the cytoplasm of tumor cells,rather than in the nucleus.

The significanceof this phenomenon is unclear but one explanation could be that nuclear localization of cyclin B1 is transient where as cytoplasmic accumulation is continuous throughout the cell cycle in premalignant and malignant cells. ${ }^{36}$

Although there have been few studies on cyclin B1 expression on oral biopsies of squamous cell carcinomas ${ }^{31,36,37,39.40,41}$, the expression of cyclin B1 in clinically normal mucosa of dysplastic(tobacco habituated)individual has not been studied.

\section{Bibliography}

[1]. Yogesh more, anil k D cruz, oral cancer review of current management strategies, the national medical journal of india. 2013;26(3): $152-158$.

[2]. Carcinogenesis from Wikipedia, the free encyclopedia. Kataleen Collins, tyler jacks, nikklap.pavletics, the cell cycle and cancer, science sessions, the PNAS podcost program.

[3]. D.G Johnson and C.L walker, cyclins and cell cycle cheekpoints, annual rev. pharmacol toxild.99; 39:295-312.

[4]. CCNB1 (cyclin B1) 3:Surgical factors Atlas of Genetics and cytogenetics in oncology and Haematology. Crispianscully, oral cancer aetiopathogenesis; past, present and future aspects Med oral pathology oral cirbucal. 2011; 1:16(3): 306-11.

[5]. Head and neck cancer, internet. Liviu feller, johanlemmer, oral squamous cell carcinoma; epidemiology, clinical presentation and treatment. Journal of cancer therapy. 2012; 3: 263-268.

[6]. Benedikt J. folz ${ }^{\mathrm{a}}$, corle E silver ${ }^{\mathrm{b}}$, Alessandra rinoldo ${ }^{\mathrm{c}}$, Johannes $\mathrm{J}$ fayan ${ }^{\mathrm{d}}$, loring W pratt $^{\mathrm{e}}$, Neil weir ${ }^{\mathrm{f}}$, Danidaseitz ${ }^{\mathrm{g}}$, al fioFerlito ${ }^{\mathrm{c} . *}$. oral oncology. 2008;44: 2-9

[7]. Luciana S. Marocchio ${ }^{1}$, Joelma lima ${ }^{1}$, Felipe F.sperandio ${ }^{1}$, Luciana correa ${ }^{2}$, suzana O. M.de sousa ${ }^{1}$. Journal of oral science. 2010; 52(2): 267-273.

[8]. G.kiran, NDVN shyam, Jagdeeshwarrao, A Krishna, B shridharreddy, N Prasad. Demographics and histopathological patterns of oral squamous cell carcinoma at a tertiary level referral hospital in Hyderabad, India: A 5 year retrospective study. JP journal. 2012; 2(4) : 198-201.

[9]. Shenoi R, devruklikar V, chaudhri ${ }^{1}$, Sharma $\mathrm{BK}^{2}$, spare $\mathrm{SB}^{2}$, chikhale $\mathrm{A}^{2}$. Demographic and clinical profile of oral squamous cell carcinoma patients: A retrospective study. Indian journal of cancer. 2012; 49(1); 21-26. 
[10]. Freddilewin, M.D ${ }^{1.2}$, staffan E. norell , M.D, hemming Johansson, B.Sc ${ }^{1}$, per gustavsson, M.D ${ }^{3}$. johanwennerberg, M.D ${ }^{4}$. smoking tobacco, oral snuff, and alcohol in the etiology of squamous cell carcinoma of the head and neck.

[11]. Sachinjindal, Islitacraulan, harshminderkaurgrewal, alteration in buccal mucosal cells due to the effect of tobacco and alcohol by assessing the silver stained nucleolar organizer regions and micronuclei, journal of cytology. 2013;30(3): 174-178.

[12]. Jukka H Meurman, infections and dietary risk factors of oral cancer, journal of oral oncology. 2010;46: 411-413.

[13]. Craig S miller, DMD, $\mathrm{MS}^{\mathrm{a}}$, and bryan $\mathrm{M}$. johnstone, $\mathrm{phD}^{6}$, Lexington, $\mathrm{ky}$, and irdianapolis, human papilloma virus as a risk factor for oral squamos cell carcinoma: a meta analysis, 1982-1992 journal of oral surgery, oral medicine oral pathology. 2001;91(6):622635.

[14]. Miller C S, johnstone BM, is human papilloma virus a risk factor for oral squamous cell carcinoma?, Oral surgery and oral medicine oral pathology oral radiology endodontics. 2001;92:170-179.

[15]. Jatin $\mathrm{k}$ nagpal; srinivas pathaik ${ }^{1}$, bibhu $\mathrm{R}$ das ${ }^{1,2^{*}}$, prevalence of high risk human papilloma virus types and its association with $\mathrm{p}_{53}$ codon 72 polymorphism in tobacco addicted oral squamous cell carcinoma (oscc) patients of eastern Indian, int.J.cancer. 2032;97:649-653.

[16]. William $\mathrm{h}$ westra, the changing face of head and neck cancer in the $21^{\text {st }}$ century: the impact of HPV on the epidemiology and pathology of oral cancer. Journal of head and neck pathology., 2009;3:78-81.

[17]. Urmila J nair ${ }^{1,2}$, gunte obe ${ }^{3}$, marlin friesen ${ }^{1}$, mark $\mathrm{T}$ goldberg ${ }^{1,4}$, and helmat bartsch ${ }^{1}$, role of lime in the generation of reactive oxygen species from betel-quid ingradients. Journal of environmental health perspectives. $1992 ;$; 98; 203-205.

[18]. C.scully ${ }^{\mathrm{a}, *}$, J.K.field ${ }^{\mathrm{b}, \mathrm{c}}, \mathrm{Htanzawa}^{\mathrm{d}}$, genetic aberrations in oral or head and neck squamous cell carcinoma 2: chromosomal aberrations. Journal of oral oncology. 2000;36:311-327.

[19]. Winston Patrick kuo,DDS,Ms, tor-kristianjenssen,Msc, peter j.park,phd, marks W.lingen,DDS,phd, rifatharinaDDS,phd, lucica oliro-machado,MD,phd ${ }^{1}$. Journal of annual symposium. 2002; 415-419.

[20]. Mehrotra R, yadav S, oral squamous cell carcinoma ; etiology, pathogenesis and prognostic value of genomic alterations, Indian journal of cancer. 2006; 43(2): 60-66.

[21]. C.scully, ${ }^{\mathrm{a}, *}$ J.K field ${ }^{\mathrm{b}, \mathrm{c}}, \mathrm{H}$. Tanzawa ${ }^{\mathrm{d}}$, genetic aberrations in oral or head and neck squamous cell carcinoma:1. Carcinogen metabolism, DNA repair and cell cycle control oral oncology. 2000; 36: 256-263.

[22]. Snehal G patel and jatin p. shah, TNM staging of cancers of the head and neck: striving for uniformity among diversity. A cancer journal for clinicians. 2005; 55: 242-258.

[23]. Ankurbhargava, sonalsaigal, nuralichalishazar, histopathological grading systems in oral squamous cell carcinoma: a review journal internal oral health. 2010,2(4): 1-10.

[24]. Doshineena $\mathrm{p}^{1}$, shah siddharth $\mathrm{A}^{2}$, patelkeyur $\mathrm{B}^{1}$, jhabnawalamuhira $\mathrm{F}^{3}$, histological grading of oral cancer: a compassion of different systems and their relations to lymphnode metastasis, national journal of community medicine. 2001:2(1):136-142.

[25]. R.A Morelatto ${ }^{1,2}$, M.C. Herrera ${ }^{1,2}$, E.N. Fernadez ${ }^{2}$, A.G $>$ corball $^{2}$, S.A lopez de blanc ${ }^{1,2}$, journal of oral pathology medicine, 2007;36:405-8.

[26]. Cyclin from Wikipedia, the free encyclopedia.

[27]. khaledA.Hassan,K.kianAng 2,Adel K.EL-Naggar,MichalD.Story,JancetI.Lee,DianeLiu,cyclin B1 over expression and Resistance to Radiotherapy in Head and Neck squamous cell carcinoma,The American journal of cancer.2,2002.

[28]. .Jennifer Kushner, ${ }^{1}$ Grace Bradley, ${ }^{1}$ Beverley young, ${ }^{2}$ and Richard c.k.Jordan,journal of oral pathology medicine.1999;28:77-81.

[29]. Anjahagting, Christina karlsson,parlclute, mark Jackson and pines,Mpf localization is controlled by nuclear export, the EMBO journal. 1998;17(14): 4127-4138

[30]. Catherine G Takizawa and David o Morgan,control of mitosis by changes in the subcellular location of cyclin- B1-cdk1 and cdc 25 c,current opinion in cell biology.2000,12:658-665.

[31]. Anna G zygogianni ${ }^{1 *}$, George kyrgias $^{2}$, petros karakitcos ${ }^{3}$, amanta psyrri $^{4}$, john konvaris ${ }^{1}$, nikoloas kelekis ${ }^{1}$, vassilis kouloulias ${ }^{1}$. Head and neck oncology. 2011; 3(2) 1-12.

[32]. Heike Grabsh, ${ }^{1} \mathrm{MD}$, Kristina Lickvers,MD, ${ }^{2}$ Olaf Hansen, ${ }^{3}$ Shinsuke takeno,MD,${ }^{4}$ reinhart willers,Phd,${ }^{5}$ Wolfgang stock,MD, ${ }^{6}$ prognotic value of cyclin B1 protein expression in colorectal cancer,jornal $\mathrm{f}$ American society for clinic patklogy.2004;511-516.

[33]. khaledA.Hassan,Adel K.EL-Naggar,Jean-Charles soria,DianLiu,WaunK.Hong,Li Mao 2,clinical significance of cyclin B1 protein expression in squamous cell carcinoma of the tongue,The American journal of cancer.2001.

[34]. H.Harda,K.omura,yNakajima,S Hasegawa and S.Mogi,J.Exp,clin.cancer research.2006;25:3.

[35]. Satirowatanafe, rogerio ${ }^{1}$, angelica $\mathrm{F}$ oton-leite ${ }^{1}$, rita de $\mathrm{C} \mathrm{G}$ alencer $^{2}$, josec oliverira ${ }^{2}$, clordio $\mathrm{r}$ leles ${ }^{3}$, et al. analyses of cell proliferation and pattern of invasion in oral squamous cell carcinoma, journal of oral science. 2010; 52(3): 417-424.

[36]. THOmasK.Hoffmann,SokratisTrellakis,Korneliaokulicz,Patrickschuler,Jensgreve,JudithArnolds,cyclin B1 expression and p53 status in squamous cell carcinomas of the Head and neck,journal of Anti cancer research.2011;31:3151-3158.

[37]. Gururaj B Patil,Kaveris.Hallikeri,Aswiniy.Baiappanavar,sudheerG.Hongal,PR.Sanjaya,andsheetalkumarG.sagari,cyclin B1 overexpression in conventional oral squamous cell carcinoma and verrucous carcinoma-A correlation with clinicopathologicalfeatures,journal of medical oral patol oral cir Bucal.2013;18(4).

[38]. Jean-Charles soria,SejinJang,FadloR.Khuri,etal,journal of cancer research.2000;60:4000-4004.

[39]. P.K. Tsantonlis ${ }^{\mathrm{a}}$, N.G. kastrinakis ${ }^{\mathrm{a}}$, A.D tourvas ${ }^{\mathrm{a}}$, laskaris ${ }^{\mathrm{b}}$, V.G gorgoulis ${ }^{\mathrm{a}}{ }^{*}$, adavances in the biology of oral cancer oral oncology. 2007;43: 523-534.

[40]. Jamilehbeigomtaberi; soheila nasiri ${ }^{2}$, fatemer namazi ${ }^{3}$, niha hamian ${ }^{4 *}$, mahin bakasha ${ }^{5}$, maryam boharvand ${ }^{6}$, hamed mortazavi ${ }^{7}$, prevalence of squamous cell carcinoma in a defined population in iran over the last 10 years, asian journal of pharmaceutical and health sciences. 2014;4(1): 948-950.

[41]. C.D.Llewellyn, N.W. Johnson, K.A.A.S, warnakulasuriya, journal of oral oncology. 2001;37: 401-418.

[42]. M.akhter, S hossain, quazi B rahman, motinr R molla, a study on histological grading of oral squamous cell carcinoma and its co relationship with regional metastasis. Journal oral maxillofacial pathol. 2011;15(2): 168-176.

[43]. Van LeukenR,clijstersL, Wolthuis R.TO cell cycle,swing the APC/C.BiochimBiophys ACTA.2008;1786:49-59.

[44]. Wary K.K and Sharan R.N.1988 "Aquous extracts of betel nut of north east india induces DNA strand breaks and enhances rates of cell proliferation in vitro".J Cancer Res Clin Oncol.114:579-82.

[45]. Davis CD,T SujiPA,MiluerJA,selenoproteions and prevention.Annual Review of Nutrition .2012;32:73-95.

[46]. AnnerothG,Batsakis J, lunaM.Review of literature and a recommended system of malignancy grading in oral squamous cell carcinoma,sland J Dent .Res.1987;95:229-49.

[47]. BryneM,BoysenM,Alfsenc,AbelerVE.Incasive front of carcinomas.The most important Area tumor prognosis,Anticancer. Res.1998;18:4757-64. 